\title{
PEMANFAATAN APLIKASI MOBILE KITABISA DALAM PELAKSANAAN CROWDFUNDING DI INDONESIA
}

\author{
Nurul Hutami ${ }^{1}$, Irwansyah ${ }^{2}$ \\ 1) Mahasiswa Pascasarjana Program Studi Ilmu Komunikasi Universitas Indonesia, \\ 2) Staf Pengajar Pascasarjana Ilmu Komunikasi, Fakultas Ilmu Sosial dan Ilmu Politik Universitas \\ Indonesia \\ Email : nurulhutami@gmail.com
}

\begin{abstract}
ABSTRAK
Adanya internet tentunya tidak hanya membantu kehidupan manusia, tetapi lambat laun juga mengubahnya. Kecenderungan untuk mengakses internet pun kian berubah, termasuk dari penggunaan perangkat yang dipilih. Meningkatnya penggunaan internet, membuat praktik crowd semakin mulai dikenal dan diterapkan dalam berbagai keperluan, misalnya crowdfunding. crowdfunding dapat diartikan sebagai panggilan atau penawaran terbuka yang bisanya dilakukan dengan internet guna penyediaan sumber daya keuangan, baik dalam bentuk sumbangan atau pertukaran produk masa depan atau bentuk penghargaan tertentu dan hak suara. Oleh karena popularitas aplikasi seluler program komputer kecil yang dirancang untuk beroperasi terutama di dalam smartphone dan komputer tablet juga telah mengalami pelonjakan, peneliti ingin mengetahui pemanfaatan aplikasi yang digunakan oleh Kitabisa dalam melaksanakan praktik crowdfunding. Dengan metode penelitian kualitaif dan sumber data sekunder, peneliti berusaha memaparkan gambaran pemanfaatan aplikasi Kitabisa, baik di perangkat yang bersistem operasi iOS dan android. Dari hasil pembahasan penelitian ini dapat disimpulkan bahwa aplikasi Kitabisa terus dipromosikan dengan terus menambahkan fitur menarik agar tetap dapat mempermudah para pemberi dana dalam memberikan donasinya.
\end{abstract}

Keyword : Aplikasi, Mobile, Crowdfunding.

\section{ABSTRACT}

The existence of the internet does not not only help human life, but also change it slowly. Nowadays, the tendency to access the internet has also changed, including the use of selected devices. The increasing usage of the internet, making crowds known and applied in various purposes, such as crowdfunding. crowdfunding can be interpreted as an open offer or offer that is usually done on the internet to provide financial resources, either in the form of contributions or the provision of future products or special forms of appreciation and voting rights. Because the usage of popular mobile applications - small computer programs specifically designed to support smartphones and tablet computers - are also increasing, researchers want to get know further about applications used by Kitabisa in crowdfunding practices. With qualitative research methods and secondary data sources, researchers tried to explain application, both on $\mathrm{IOS}$ and Android operating systems. From the results of the discussion of this study, we may conclude that the application continues to be promoted by continually adding attractive features to make it easier for funders to make donations.

Keywords: Application, Mobile, Crowdfunding. 


\section{PENDAHULUAN}

Internet merupakan kemampuan penyiaran di seluruh dunia yang berlangsung secara bersamaan, suatu mekanisme untuk penyebaran informasi, dan media untuk kolaborasi dan interaksi yang terjadi di antara individu-individu serta komputer mereka tanpa memperhatikan lokasi geografis. Internet juga merupakan salah satu bukti kesuksesan dari manfaat investasi yang berkelanjutan serta komitmen terhadap penelitian dalam bidang pengembangan infra struktur informasi. Bermula dari suatu penelitian, pemerintah, industri serta akademisi telah menjadi mitra dalam mengembangkan dan menggunakan teknologi ini (Leiner et al., 1997).

Kecenderungan untuk mengakses internetpun kini kian berubah, termasuk dari penggunaan perangkat yang dipilih. Orangorang telah beralih dari ponsel biasa ke ponsel pintar, baik di negara maju maupun berkembang (Han \& Wong, 2013). Berdasarkan data dari consumer barometer yang disediakan oleh Google, ditemukan data bahwa $81 \%$ akses internet di Indonesia dilakukan melalui smartphone (Google, n.d.). Hal tersebut secara jelas menunjukkan bahwa revolusi mobile telah berada di sekitar kita. Istilah mobile adalah perangkat media yang intim, personal, dan portabel, dan juga disebut sebagai 'layar keempat' setelah layar bioskop, televisi, dan komputer (Goggin \& Goggin, 2014). Terdapat dua pendekatan untuk penggunaan mobile, yaitu :

1. aplikasi - baik aplikasi asli maupun aplikasi hybrid

2. situs mobile (Han \& Wong, 2013)
Perkembangan mobile dari segi industri, bisnis, dan usaha dalam perspektif industri teknologi komunikasi menarik jika dilihat dari empat sisi yaitu, pertama, adanya jaringan data berkecepatan tinggi yang dapat mendukung pengguna. Kedua, adanya pengembangan perangkat teknologi yang memiliki performa tinggi dengan harga kompetitif dengan beragam kapasitas penyimpanan dan processing Ketiga, adanya marketplace untuk aplikasi yang mudah digunakan oleh pengguna serta dapat memberikan support bagi adanya pengembangan industri aplikasi. Keempat, meningkatnya kebutuhan manusia untuk menggunakan aplikasi yang praktis. Dengan semakin meningkatnya penggunaan mobile, banyak perusahaan atau organisasi yang berkeinginan untuk membuat aplikasi yang lebih mudah diakses oleh pengguna (Tracy, 2012).

Adanya internet tentunya tidak hanya membantu kehidupan manusia, tetapi lambat laun juga mengubahnya. Terlebih lagi, karena internet kini dapat secara mudah diakses secara mobile pada smartphone. Kemudahan tersebut dapat terlihat misalnya dengan penyediaan layanan yang biasa dilakukan secara offline, yang kini juga dapat diakses secara online.

Meningkatnya penggunaan internet, membuat praktik crowd semakin mulai dikenal dan diterapkan dalam berbagai keperluan, misalnya crowdfunding. Pengembangan teknologi kolaboratif dalam domain sistem informasi memungkinkan para enterpreneur untuk memiliki cara baru dalam mendapatkan dukunganfinansial.Alternatifdukunganfinansial ini disebut crowdfunding. Crowdfunding merupakan cara untuk mengumpulkan uang secara online dari orang-orang tanpa kontak 
pribadi. Dalam prosesnya, crowdfunding tergolong sederhana. Jadi, pengusaha, yang juga dikenal dalam proses crowdfunding sebagai pendiri proyek memposting ide proyeknya dalam platform penggalangan dana online, serta calon investor yang memiliki minat dalam proyek ini. Platform crowdfunding disini memiliki fungsi untuk membantu para enterpreneur membangun halaman web semiterstruktur untuk mengiklankan ide mereka dan juga menyediakan kesempatan bagi kosumen untuk menerima produk atau servis sebelum proses pemasaran.

Kunci utama dari crowdfunding adalah kearifan kolektif bekerja dengan baik ketika mengevaluasi sebuah proyek. Dalam crowdfunding, enterpreneurpun tidak menghadapi resko kehilangan kendali pada perusahaan mereka ketika mereka mencari dana tambahan. Crowdfunding pun berfungsi sebagai indikator jika pasar memiliki produk atau servis baru (Kim, Por, \& Yang, 2017). Menambahkan definisi sebelumnya, crowdfunding dapat diartikan sebagai panggilan atau penawaran terbuka yang bisanya dilakukan dengan internet guna penyediaan sumber daya keuangan, baik dalam bentuk sumbangan atau pertukaran produk masa depan atau bentuk penghargaan tertentu dan hak suara (Belleflamme, Lambert, \& Schwienbacher, 2013).

Massolution mengklasifikasikan crowdfunding menjadi 4 kategori yaitu (Massolution, 2012) :

1. Equity-based crowdfunding, yaitu donatur sebagai pemberi dana menerima adanya bentuk kompensasi dalam bentuk ekuitas atau pendapatan atau pengaturan saham dari hasil proyek.
2. Lending-based crowdfunding, yaitu donatur sebagai pemberi dana menerima adanya kompensasi yang diperoleh secara berkala atau bunga. Donatur kemudian memperoleh pembayaran kembali dari dana yang dipinjamkan jika proyek sudah dianggap sukses.

3. Reward-based crowdfunding, yaiti donatur sebagai pemberi dana memberikan dana untuk memperoleh keuntungan atau kompensasi yang berbentuk selain uang.

4. Donation-based crowdfunding, yaitu donatur sebagai pemberi dana tidak mengharapkan imbalan dari orang yang menginisasi proyek.

Apabila equity-based dan lending-based crowdfunding lebih cocok bagi proyek yang berkaitan dengan game, aplikasi, atau produk digital, kampanye donation-based dan rewardbased crowdfunding dilaksanakan berdasarkan suatu penyebab dan dianggap mampu menarik keyakinan pribadi dari para pemberi dana (Massolution, 2012).

Menurut Hemer, klasifikasi crowdfunding dapat dibagi sebagai berikut (Hemer, 2011):

1. Jika dilihat berdasarkan latar belakang komersial atau tujuan proyek :

a. Not-for-profit: proyek didirikan atas tujuan untuk kepentingan sosial, seperti bidang kesehatan masyarakat, sarana dan prasarana umum, proyek penelitian untuk umum, dsb.

b. For profit: proyek didirikan atas tujuan komersial, mencakup promosi produk, promosi film atau musik, pendirian usaha baru, dsb.

c. Intermediate: proyek yang belum jelas akan masuk di kategori manapun 
karena latar belakang komersialnya belum jelas.

2. Jika dilihat berdasarkan kelekatan organisasi awal :

a. Independent and single: inisiatif proyek dirancang oleh individu.

b. Embedded: inisiatif proyek berasal dari organisasi publik atau swasta dan ditujukan di awal sebagai bagian dari organisasi tersebut.

c. Start-up: inisiatif proyek berasal dari pihak mandiri, namun mengarah ke organisasi yang memiliki lingkup terbatas.

Untuk memulai atau mengembangkan ide, dana tentunya dibutuhkan sebagai hal yang paling penting (Handojo \& Wibowo, 2012). Kesulitan pendanaan yang sebelumnya dapat didukung dari bank serta lembaga finansial lainnya bukanlah tanpa sebab. Biasanya, ide inovatif tidak dapat divalidasi dalam pasar yang sifatnya konvensional karena kurang realistis untuk membujuk para investor (Kim et al., 2017).

Tantangan lainnya adalah sulitnya menemukan sarana publikasi. Publikasi merupakan salah satu hal yang berperan penting dalam penggalangan dana karena dapat membantu mencapai jumlah dana yang ingin didapatkan. Dengan kata lain, semakin baik suatu publikasi tersebut dilaksanakan, maka semakin besar pula kemungkinan pencapaian dana tersebut didapatkan (Handojo \& Wibowo, 2012).

Jika dilihat dari segi pemberi dana, manusia sebagai makhluk sosialpun memiliki keinginan untuk saling menolong satu sama lain. Baik individu ataupun organisasi yang berniat menjadi pemberi dana sering menemukan kendala, yakni kurangnya sarana informasi terkait proyek atau kegiatan yang membutuhkan dana. Selain itu, sarana perantara untuk menyalurkan dana ke proyekproyek yang membutuhkan pun masih kurang (Handojo \& Wibowo, 2012).

Seiring perkembangan zaman, jika sebelumnya, penggalangan dana dapat dilakukan secara offline, namun karena kehadiran internet, kini donasi dapat dilakukan secara online. Oleh karena perkembangan teknologi pun, secara online manusia tidak hanya dapat mengaksesnya melalui web saja, namun kini layanan-layanan tersebut juga dapat diakses melalui aplikasi.

Saat ini, memang tidak hanya smartphone, popularitas aplikasi seluler --program komputer kecil yang dirancang untuk beroperasi terutama di dalam smartphone dan komputer tablet-juga telah mengalami pelonjakan.(Eden, Jong, \& Buningh, 2016). Penerapan dan penggunaan aplikasi yang ada di ponsel telah meledak sejak Apple meluncurkan iPhone dan perilisan dari sistem operasi Android yang dimiliki oleh Google (Tracy, 2012).

Jika ditinjau dari definisinya, aplikasi dapat diartikan sebagai jenis perangkat lunak yang memungkinkan pengguna untuk melakukan tugas tertentu yang dapat diinstal dan dijalankan pada berbagai perangkat digital portable, seperti ponsel pintar dan tablet (Liu, $\mathrm{Au}, \&$ Choi, 2015). Definisi lainnya yang lebih spesifik untuk mobile app,yaitu program komputer kecil yang dirancang untuk berjalan terutama smartphone dan komputer tablet (Eden et al., 2016).

Perkembangan aplikasi dimulai pada 
Oktober 2007, ketika perusahaan Apple meng-umumkan bahwa developer dapat membuat aplikasi dalam iPhone. Keputusan untuk mengizinkan aplikasi asli dalam iOS menciptakan model bisnis baru untuk pengembang telah mengubah proyek berskala kecil menjadi ledakan mobile (Gowell \& Mcwherter, 2012). Konsep keterbukaan pada pembuatan aplikasi yang diumumkan oleh Apple pada tahun 2007 disebabkan karena platform Android diperkirakan akan diluncurkan segera pada masa itu. Android yang menjadi kompetitor Apple merupakan platform yang terbuka dan fleksibel, sehingga developer dapat melakukan hal yang tidak bisa mereka lakukan didalam iOS (Gowell \& Mcwherter, 2012).

Salah satu penyedia crowdsfunding donasi, baik secara web maupun aplikasi, adalah Kitabisa. Kitabisa.com adalah salah satu perusahaan yang bergerak di bidang sosial atau social enterprise yang memanfaatkan mutakhirnya ilmu teknologi sebagai pengelola finansial pengumpulan dana (fundraising) yang berbasis digital (crowdfunding) (Ardiansyah, 2018).

Situs web ini berada di bawah bimbingan Rhenald Kasali dan "Rumah Perubahan" miliknya. Kitabisa.com adalah crowdfunding sosial pertama di Indonesia yang mengedepankan konsep kolaborasi sosial, yaitu keyakinan jika ingin membentuk suatu perubahan, masing-masing orang harus bergabung serta berkontribusi dengan memberikan pertolongan apa saja yang mampu diberikan (Irfan, Mahasiswa, \& Sosial, n.d.).

Dikutip dari situs webnya, Kitabisa didirikan sejak tahun 2013, Kitabisa berperan sebagai wadah serta teknologi online bagi penggalang dana yang disebut dengan \#OrangBaik yang memiliki niat untuk :

1. Menggalang dana dengan membuat donasi online (disebut juga dengan halaman penggalangan) untuk aneka tujuan sosial, personal, kreatif, dan sebagainya.

2. Mengirim donasi kapanpun secara online ke penggalangan di Kitabisa yang cocok dengan kategori atau organisasi yang ia minati atau pedulikan.

Kitabisa merupakan perusahaan yang menganut kebijakan open platform, yang berarti semua orang dapat saja memiliki kesempatan yang sama untuk membuat halaman donasi di Kitabisa selama penggalang dana tersebut memenuhi syarat, seperti verifikasi identitas serta tidak melanggar hukum yang ada di Indonesia.

Berkaitan dengan biaya untuk operasional, sebagai social enterprise startup, Kitabisa menetapkan adanya pembiayaan administrasi sebesar 5\% dari total donasi yang ada di sebuah halaman donasi online, namun untuk penggalangan bencana alam dan zakat akan dikenakan $0 \%$ biaya administrasi. Dengan model ini, Kitabisa dapat fokus mengembangkan teknologi serta layanan guna secara terus menerus mempermudah kegiatan donasi di Indonesia. Kitabisa juga memiliki perizinan serta bersifat legal karena tercatat di Kemenkumham dan diaudit oleh Kantor Akuntan Publik dengan hasil Wajar Tanpa Pengecualian (Kitabisa, n.d.). Dengan adanya fenomena Kitabisa sebagai penyedia crowdfunding yang memanfaatkan situs web dan aplikasi, melalui penelitian ini, peneliti 
ingin mengetahui pemanfaatan aplikasi yang digunakan oleh Kitabisa dalam melaksanakan praktik crowdfunding.

\section{METODE PENELITIAN}

Penelitian ini adalah penelitian dengan metode kualitatif. Metode penelitian ini juga tergolong postpositivistik karena berlandaskan atas filsafat postpositivisme, serta sebagai metode artistik karena proses penelitian ini lebih bersifat seni atau kurang memiliki pola. McMillan dan Schumacher (1997) mengartikan metode kualitatif sebagai tradisi tertentu dalam ilmu pengetahuan sosial yang secara fundamental bergantung pada pengamatan terhadap manusia dalam kawasannya sendiri dan berhubungan dengan orang-orang tersebut dalam bahasanya dan dalam peristilahannya. Peneliti juga memanfaatkan sumber data sekunder atau data yang didapatkan dari dokumen-dokumen grafis (tabel, catatan, notulen, rapat, dll),foto-foto, film, rekaman video, benda-benda, dan lain-lain.

\section{HASIL PENELITIAN}

Dalam perannya sebagai penyedia layanan donasi secara online yang tidak memberikan imbalan kembali bagi donaturnya, Kitabisa termasuk ke dalam jenis donationbased crowdfunding. Kitabisa tidak memberikan imbalan apa-apa kepada pengguna yang sekaligus menjadi pemberi dana selain info yang terus diperbarui terkait donasi yang diberikan.

Berdasarkan latar belakang komersial atau tujuan proyeknyapun, aplikasi Kitabisa termasuk ke dalam not-for-profit crowdfunding karena proyek-proyek di dalamnya didirikan atas tujuan-tujuan yang berkaitan dengan berbagai kepentingan sosial, seperti bantuan kemanusiaan, kesehatan, pendidikan, sarana dan infrastruktur, lingkungan, serta hewan. Namun, apabila ditelaah klasifikasinya berdasarkan kelekatan organisasi awal, aplikasi crowdfunding Kitabisa ini memfasilitasi dua jenis, yaitu independent and single (karena proyek dapat dirancang oleh individu) dan embedded (karena proyek juga dapat diinisasi oleh organisasi). Hal tersebut dapat dilihat dari gambar di bawah ini yang menunjukkan keberagaman inisiator proyek, seperti Jennifer Bachdim dan Herawati selaku independent and single crowdfunding dan Kampung Lentera sebagai bentuk dari embedded crowdfunding.

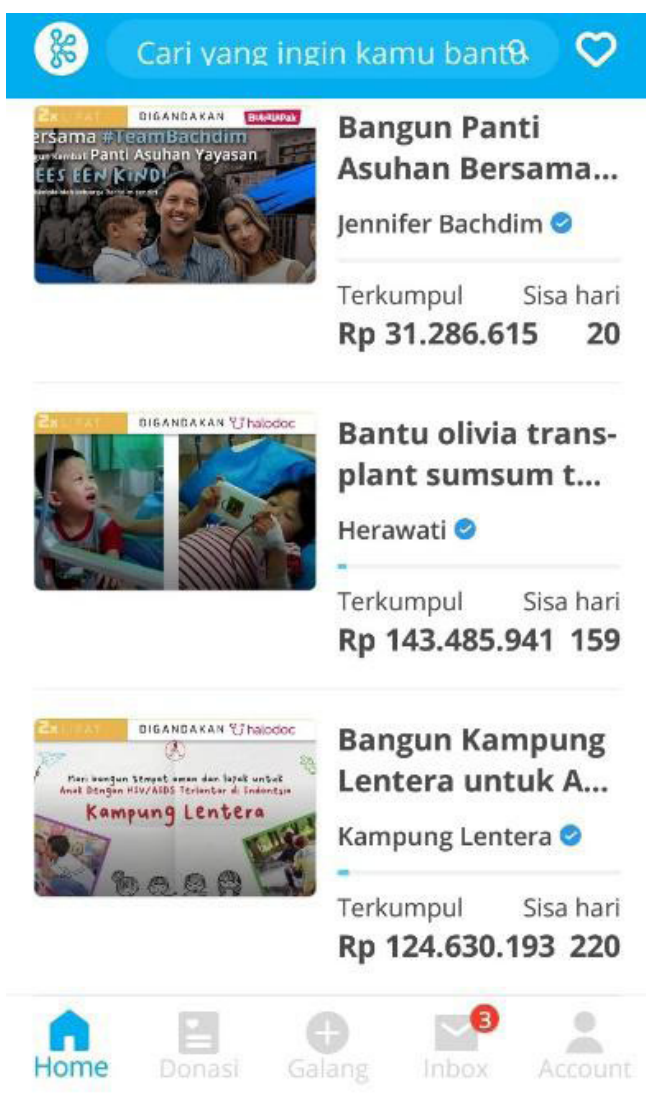

Gambar 1.

Individu dan organisasi yang menjadi inisator proyek di dalam aplikasi Kitabisa 
Di dalam playstore yang ada di perangkat dengan sistem operasi Android, aplikasi "Kitabisa-Donasi \& Zakat Online" ini termasuk dalam jenis aplikasi lifestyle. Dalam keterangan pun, aplikasi ini pertama kali dirilis pada tanggal 23 Juni 2017 dan hingga bulan Mei 2019 tercatat sudah diunduh lebih dari 100.000 kali. Aplikasi ini pun memiliki nilai cukup baik, yaitu 4,7 dari 5 sebagai bentuk penilaian dari para pengguna.

Berbeda dengan aplikasi pada smartphone Android, berdasarkan informasi dari video yang berjudul "Aplikasi yang Ditunggutunggu" (https://www.youtube.com/watch?v= HgkH6uyKZCo) pada channel Youtube Kitabisa com, aplikasi Kitabisa baru dapat diunduh secara gratis bagi pengguna iOS di Appstore sejak 21 Mei 2019.

Dilansir dari video dalam channel Youtube resmi Beritasatu berjudul "Mengenal Startup Crowdfunding Kitabisa” (https://www.youtube. com/watch? $v=$ cKLIDcdu3zQ) yang diunggah pada Oktober 2018 lalu, di tahun peluncurannya, yakni 2017, aplikasi mobile Kitabisa di android juga diklaim menjembatani hampir dari $72 \%$ dari seluruh kegiatan penggalangan dana yang dilakukan oleh donatur. Kitabisa di tahun 2017 mencatat terdapat lebih dari 12.000 kampanye penggalangan dana dengan berbagai macam topik dan isu sosial. Dibandingkan dengan tahun 2016, pencapaian ini menunjukkan peningkatan yang cukup signifikan, yakni mencapai 300\% dengan pertumbuhan donasi hingga 230\%. Tiga jenis kampanye Kitabisa yang paling populer di tahun 2017 yakni membantu keluarga atau teman yang sakit sebesar $24 \%$, isu kemanusiaan sebesar $16 \%$, dan pembangunan tempat ibadah sebesar $10 \%$.
Dilansir dari video pada channel Youtube resmi Kitabisa com yang mempromosikan aplikasi dengan judul "Aplikasi Untuk Bantu Orang Setiap Hari” (https://www.youtube.com/ watch?v=ViEUtbgzLu0), aplikasi Kitabisa hadir sebagai solusi bagi orang yang belum mengetahui sasaran donasi secara rutin yang tepat. Dilengkapi dengan banyaknya pilihan penggalangan dana, penggunapun disuguhkan dengan konten narasi yang juga menjadi sumber informasi berkaitan dengan pihak yang ingin dibantu. Selain kemudahan berbagi, aplikasi ini juga menjunjung tinggi transparansi dengan mengedepankan informasi terbaru mengenai dampak donasi yang dilaksanakan di dalamnya. Aplikasi ini juga dapat membantu mengingatkan pengguna untuk berbagi setelah menerima gaji bulanan.

Sebagai keunggulannya, Kitabisa juga memaparkan beberapa poin dalam keterangan di Appstore dan playstore yang dapat dibaca pengguna pada kolom "About this app". Beberapa keunggulan tersebut disimpulkan dalam poin sebagai berikut :

1. Kemudahan berdonasi dan berzakat secara mudah dan cepat karena dengan aplikasi "Kitabisa-Donasi \& Zakat Online", waktu yang diperlukan hanya 11 detik.

2. Donasi yang dapat disalurkan mulai dari Rp 1.000

3. Kitabisa bekerjasama dengan lima bank nasional, seperti bank BCA, Mandiri, BRI, BNI, dan BNI Syariah sebagai mitra pembayaran donasi dan zakat.

4. Selain perbankan, Kitabisa juga bekerjasama dengan Go-pay dan Dompet Kebaikan sebagai mitra pembayaran donasi dan zakat non perbankan. 
5. Terdapat fitur "giving streak" agar pengguna aplikasi mampu memantau catatan kebaikan yang dilakukan atau donasi rutin.

6. Terdapat fitur "update" yang dapat memudahkan pengguna untuk memperoleh laporan donasi secara transparan, baik yang ditulis langsung oleh penggalang dana maupun tim Kitabisa.

7. Terdapatfitur "Kalkulator Zakat" yang dapat membantu pengguna untuk mengetahui penghitungan pembayaran zakat.

8. Untuk pembayaran zakat, Kitabisa juga bekerjasama dengan beberapa mitra Lembaga Amil Zakat (LAZ), seperti Badan Amil Zakat Nasional (BAZNAS), Dompet Dhuafa (DD), Global Zakat - Aksi Cepat Tanggap (ACT), Lazisnu (NU Care), Lazismu (Muhammadiyah), Baitul Maal Hidayatullah (BMH), Rumah Yatim, Griya Yatim Dhuafa,dan Rumah Zakat.

Seluruh donasi tidak hanya dikumpulkan oleh Kitabisa, tetapi juga dapat diurutkan berdasarkan tiga jenis, yaitu trending, akan berakhir, dan terbaru. Donasi juga dapat diklasifikasikan ke dalam beberapa 20 kategori yang dapat difilter oleh pengguna. Beberapa kategori tersebut adalah balita \& anak sakit, bantuan medis \& kesehatan, bencana alam, kemanusiaan, rumah ibadah, kegiatan sosial, beasiswa \& Pendidikan, zakat, sarana \& infrastruktur, run for chairity, kategori lainnya, panti asuhan, hadiah \& apreesiasi, birthday fundraising, difabel, menolong hewan, family for family, karya kreatif (film, buku, dll), dan lingkungan.

Terkait kategori di atas, peneliti juga mengamati penggunaan aplikasi tersebut dalam video Social Experiment yang dilaksanakan oleh beberapa public figure, seperti Chelsea
Islan, Vidi Aldiano, Gita Savitri \& Dea Azkadi , yang juga dapat dilihat dari video dalam channel Youtube resmi berjudul "Social Experiment: Chelsea Islan, Vidi Aldiano, Gita Savitri \& Dea Azkadi Nyobain Kitabisa App" (https://www. youtube.com/watch?v=5hqXyGsZjbU). Dalam video itu, ke empat public figure masingmasing diberikan uang sebesar Rp 200.000 untuk dapat mereka gunakan sebagai donasi dalam aplikasi Kitabisa sesuai dengan minat personal mereka terhadap isu-isu tertentu. Hasil social experiment tersebut menunjukkan masing-masing public figure mendonasikan uang tersebut sesuai dengan minat personal mereka terhadap isu tertentu, misalnya Chelsea Islan dan Dea Azkadi yang mendonasikannya untuk pendidikan, Vidi Aldiano mendonasikan uang tersebut untuk modal usaha, dan Gita Savitri berdonasi untuk kaum difabel.

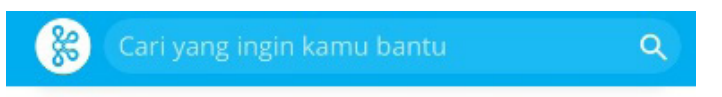

\section{Bantu siapa hari ini?}
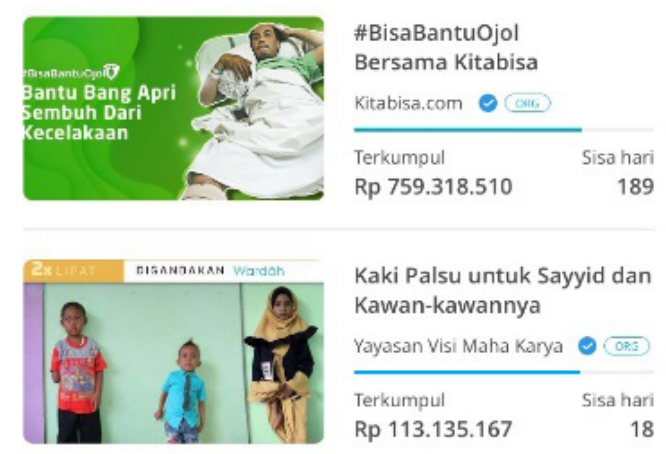

Kaki Palsu untuk Sayyid dan Kawan-kawannya

Yayasan Visi Maha Karya $\bullet$

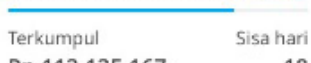

$\begin{array}{ll}\text { Rp 113.135.167 } & 18\end{array}$

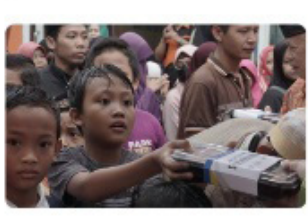

\#BukBerCeria Bersama Kaum Dhuafa KOMPAS.COM $\odot$ (InG) $\overline{\text { Terkumpul Sisa hari }}$ Rp 169.514.336 23

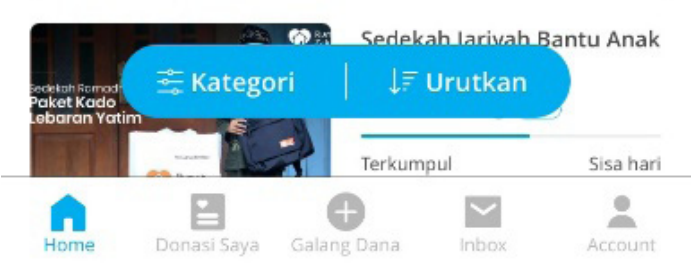




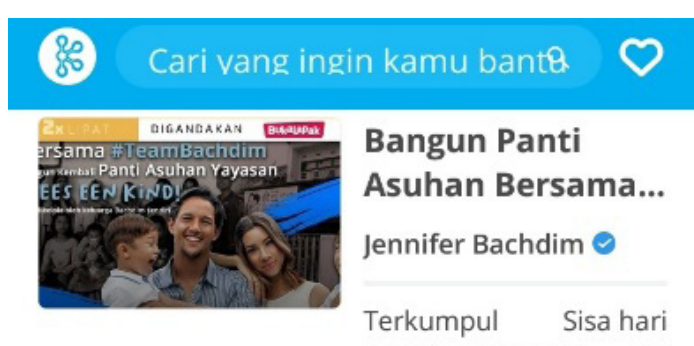

Rp 31.286.615 20

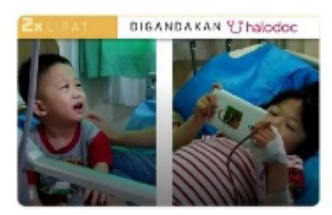

Bantu olivia transplant sumsum t...

Herawati $\odot$

Terkumpul Sisa hari

Rp 143.485.941 159

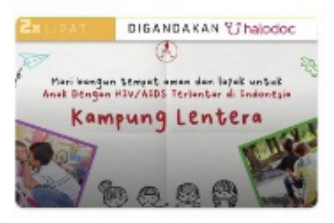

Bangun Kampung Lentera untuk A...

Kampung Lentera $\bullet$

Terkumpul Sisa hari

Rp 124.630.193 220

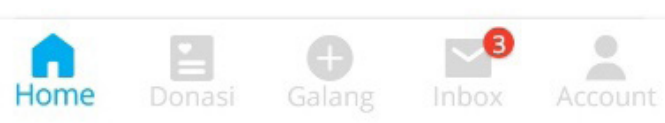

Gambar 2.

\section{Perbandingan tampilan aplikasi di smartphone} $i O S \&$ android

Apabila aplikasi Kitabisa tersebut diakses pada perangkat, baik yang bersistem operasi android maupun iOS, pengguna pertama kali akan diminta untuk mendaftarkan diri di Kitabisa. Jika sudah memiliki akun, maka pengguna pun diminta untuk masuk dengan akun mereka sendiri. Jika sudah masuk ke dalam aplikasi, pada bagian paling bawah terdapat lima menu utama, yaitu "Home”, ,'Donasi”, “Galang”, Ínbox", dan “Account”. Berikut tampilan aplikasi Kitabisa dalam perangkat android maupun iOS.

Jika bagian "Home" dipilih, terdapat pilihan untuk pembayaran zakat dan kalkulatornya. Kemudian, di bawahnya, terdapat ragam penggalangan dana beserta nama penggalang dana, dana yang sudah terkumpul,serta sisa waktu penggalangan dana. Pada bagian "Donasi", terdapat catatan donasi yang telah disalurkan oleh pengguna melalui Kitabisa. Menu ke tiga, yaitu"Galang" merupakan menu yang dipilih jika ingin berkonsultasi secara gratis sebelum melakukan penggalangan dana bersama tim Kitabisa melalui Whatsapp.

Dengan demikian, proses pembuatan kampanye penggalangan dana tidak dapat dilakukan pada perangkat smartphone. Selanjutnya, menu "Inbox" difungsikan sebagai tempat notifikasi yang dapat dibaca oleh pengguna aplikasi. Terakhir, menu "Account" merupakan pengaturan yang dapat disesuaikan langsung oleh pengguna, baik fitur "dompet kebaikan" milik pengguna, profil, pengaturan donasi, opsi keluar dari akun, kolom bantuan, syarat dan ketentuan, serta opsi untuk tidak mencantumkan nama pada saat memberikan donasi, dan opsi untuk memberi penilaian terhadap aplikasi.

Dilansir dari informasi pada playstore, terdapat beberapa kategori donasi seperti zakat fitrah, sedekah jariyah, sedekah subuh, sedekah Ramadhan, sedekah rombongan, sedekah anak yatim, dan sedekah Jumat. Selain zakat dan sedekah, jenis crowdfunding yang dilakukan Kitabisa dapat disesuaikan dengan beberapa isu yang dipedulikan, misalnya :

1. Bantuan medis

2. Beasiswa dan pendidikan

3. Panti asuhan untuk donasi anak yatim atau Hafizh Quran

4. Sarana dan infrastruktur

5. Donasi bencana alam 
6. Rumah ibadah

7. Menolong hewan

8. Lingkungan

\section{Donasi Palestina}

Guna mengantisipasi berbagai permasalahan yang terjadi pada aplikasi terkait pengiriman donasi, berdasarkan informasi dari video dalam channel Youtube resmi Berita satu berjudul "Digital Inside: Tren Donasi Digital \#1" (https://www.youtube.comwatch? $\mathrm{v}=\mathrm{CTeTk} 7 \mathrm{GWVj} \mathrm{E} \& \mathrm{t}=368 \mathrm{~s})$, Kitabisa menyediakan layanan customer happiness agar keluhan pengguna dapat terselesaikan dengan baik.

Dengan menganut konsep kolaborasi sosial dalam menangani berbagai kasus di atas, setiap orang di Kitabisa dapat memulai kontribusi dengan membuat akun dan ide penggalangan dana pun dapat didaftarkan. Meskipun saat ini dalam aplikasi tidak dapat melakukan pendaftaran ide, saat ide didaftarkan di situs web, Kitabisa memerlukan beberapa informasi, seperti latar belakang, tujuan, waktu dan tempat pelaksanaan, dan jumlah uang yang diperlukan dalam kampanye atau penggalangan dana tersebut. Jika informasi tersebut telah dicantumkan, proyek yang telah lolos kurasi oleh tim Kitabisa akan ditayangkan, baik di situs web maupun aplikasi. Dalam praktik crowdfunding, jumlah donasi per orang bukanlah hal yang penting, namun jumlah orang yang berpartisipasi (Irfan et al., n.d.).

\section{KESIMPULAN}

Perkembangan teknologi yang tidak daapt dihindari membuat satu demi satu aspek kehidupan manusia berubah mengikuti perkembangan tersebut, termasuk bagaimana pemanfaatan teknologi aplikasi yang kini dapat dengan mudah ditemui pada kehidupan sehari-hari di perangkat smartphone. Perubahan perilaku manusia yang kini semakin dekat dengan internet melalui smartphone dimanfaatkan oleh Kitabisa melalui aplikasinya.

Perusahaan yang bergerak di bidang social enterprise ini cukup mengetahui bahwa terus diperlukan inovasi agar dapat menjangkau pengguna yang juga berperan sebagai calon pemberi dana guna meraih kesuksesan dalam menjalankan praktik crowdfunding. Oleh karena itu, Kitabisa dengan dinamis mulai mendirikan situs web pada 2013, aplikasi pada perangkat bersistem operasi android pada tahun 2017, dan disusul dengan aplikasi pada perangkat bersistem operasi iOS pada tahun 2019. Perkembangan donasi yang signifikan menunjukkan bentuk kepercayaan pemberi dana terhadap situs web Kitabisa yang lebih dahulu hadir membuat Kitabisa terus berinovasi agar lebih dekat dengan penggunanya melalui aplikasi yang lebih mudah diakses pengguna sehari-hari.

Dari hasil pembahasan penelitian ini dapat disimpulkan bahwa aplikasi Kitabisa terus dipromosikan dengan terus menambahkan fitur menarik agar tetap dapat membantu pengguna, misalnya untuk menyimpan penggalangan dana favorit, mencari penggalangan dana, berdonasi melalui berbagai variasi model pembayaran, dan juga melunasi kewajiban pembayaran zakat.

Selainitu, dariaplikasi Kitabisainikitajuga dapat melihat bahwa aplikasi ini fokus terhadap 
dua kegiatan, yaitu penggalangan donasi serta pembayaran zakat. Aplikasi ini juga difokuskan bagi pengguna yang ingin menyalurkan zakat dan donasi, namun membutuhkan cara yang lebih simple dan efisien. Hal yang membedakan layanan donasi online antara di situs web dan aplikasi Kitabisa adalah ketidaksediaan fitur pembuatan kampanye penggalangan dana pada aplikasi Kitabisa.

Dengan adanya aplikasi yang dapat diakses kapanpun dan dimanapun, pengguna dapat terbantu karena secara online dapat membayarkan donasinya dengan tepat, mudah dan cepat. Tidak hanya memudahkan pengguna yang juga berperan sebagai pemberi dana, aplikasi ini juga dapat membantu pengguna mengetahui informasi secara lebih detail, baik sebelum menyalurkan dananya maupun sesudah menyalurkan dana. Keberadaan aplikasi Kitabisa juga dapat membantu pencari dana dalam menemukan sarana publikasi dan pengguna dalam menemukan sarana informasi terkait pencarian dana tersebut.

\section{DAFTAR PUSTAKA}

Ardiansyah, M. (2018). KONTRIBUSI KITABISA. COM SEBAGAI SOCIAL ENTERPRISE DALAM MEWUJUDKAN FALAH ASPEK MAKRO (PERIODE SEPTEMBER 2018). Retrieved from https://dspace.uii.ac.id/ bitstream/handle/123456789/11354/ Naskah Publikasi.pdf?sequence $=13 \&$ is Allowed $=\mathrm{y}$

Belleflamme, P., Lambert, T., \& Schwienbacher, A. (2013). Crowdfunding: Tapping the right crowd. Journal of Business Venturing. Retrieved from https://papers.ssrn.com/ sol3/papers.cfm?abstract_id $=1578175$
Eden, A., Jong, R. De, \& Buningh, S. (2016). Rousing reviews and instigative images : The impact of online reviews and visual design characteristics on app downloads Christian Burgers. https://doi. org/10.1177/2050157916639348

Google. (n.d.). Consumer Barometer - Curated Insights. Retrieved May 20, 2019, from https://www.consumerbarometer.com/en/ insights/? countryCode $=$ ID

Gowell, S., \& Mcwherter, J. (2012). Professional mobile Application Development. Indiana: John Wiley \& Sons, Inc.

Han, S., \& Wong, R. (2013). Which platform do our usersprefer :websiteormobileapp ?https:// doi.org/10.1108/00907321211203667

Handojo, A., \& Wibowo, A. (2012). Aplikasi Crowdfunding Sebagai Perantara Penggalangan Dana Berbasis Website dan Facebook Application. Komputer, 2(Jaringan Komputer), 1-5.

Hemer, J. (2011). A snapshot on crowdfunding. Retrieved from http://hdl.handle. net/10419/52302www.econstor.eu

Irfan, M., Mahasiswa, 1, \& Sosial, K. (n.d.). CROWDFUNDING SEBAGAI PEMAKNAAN ENERGI GOTONG ROYONG TERBARUKAN. SHARE: SOCIAL WORK JURNAL, 6-7. Retrieved from http://www.instink.co.id

Kim, T., Por, M. H., \& Yang, S. B. (2017). Winning the crowd in online fundraising platforms: The roles of founder and project features. Electronic Commerce Research and Applications, 25, 86-94. https://doi. org/10.1016/j.elerap.2017.09.002

Kitabisa. (n.d.). Kitabisa! - About Us. Retrieved May 20, 2019, from https://www.kitabisa. com/about-us

Leiner, B. M., Cerf, V. G., Clark, D. D., Kahn, R. E., Kleinrock, L., Lynch, D. C., ... Wolff, S. (1997). Brief History of the Internet 1997. Retrieved from http://www.acm.org 
Liu, C. Z., Au, Y. A., \& Choi, H. S. (2015). Effects of Freemium Strategy in the Mobile App Market: An Empirical Study of Google Play Effects of Freemium Strategy in the Mobile App Market : An Empirical Study of Google Play. Journal of Management Information Systems, 31(3), 326-354. https://doi.org/10.1080/07421222.2014.9 95564

Massolution. (2012). CROWDFUNDING INDUSTRY REPORT Market Trends, Com-position and Crowdfunding Platforms THE INDUSTRY WEBSITE TM. Retrieved from www.EGSllp.com
Siyoto, S., \& Sodik, M. A. (2015). DASAR METODOLOGI PENELITIAN. Literasi Media Publishing. Retrieved from https://books.google.co.id/books?id= QPhFDwAAQBAJ

Tracy, K. W. (2012). Mobile application development experiences on Apples iOS and Android OS. IEEE Potentials, 31(4), 30-34. https://doi.org/10.1109/ MPOT.2011.2182571 